\title{
Association of inflammation with worsening HOMA-insulin resistance
}

\author{
K. Park • M. Steffes • D.-H. Lee • J. H. Himes • \\ D. R. Jacobs Jr
}

Received: 2 February 2009 / Accepted: 14 July 2009 /Published online: 13 August 2009

(C) Springer-Verlag 2009

\begin{abstract}
Aims/hypothesis We examined the cross-sectional and longitudinal relationships between $\mathrm{C}$-reactive protein (CRP), a marker of low-grade inflammation, and insulin resistance and whether the association was independent of obesity and oxidative stress.

Methods CRP and insulin resistance (homeostasis model assessment of insulin resistance [HOMA-IR]) data were obtained in a population-based, prospective observational study, Coronary Artery Risk Development in Young Adults (CARDIA), during 1992-2006.

Results CRP showed a significant positive association with insulin resistance, both cross-sectionally and longitudinally (5 year follow-up). The estimated increment in HOMA-IR was $0.34 \log _{e}(\mathrm{pmol} / 1 \times[\mathrm{mmol} / 1] / 156.25) \quad(p$ value for trend $<0.0001$ ) in the highest vs lowest CRP quartiles in cross-sectional analysis, whereas the corresponding estimate was 0.12 ( $p$ trend $<0.0001)$ in the highest vs lowest CRP quartiles longitudinally over 5 years. The gradient of
\end{abstract}

K. Park $\cdot$ J. H. Himes $\cdot$ D. R. Jacobs Jr $(\bowtie)$

Division of Epidemiology and Community Health,

School of Public Health, University of Minnesota,

1300 South 2nd Street, Suite 300,

Minneapolis, MN 55454, USA

e-mail: jacobs@epi.umn.edu

M. Steffes

Department of Laboratory Medicine and Pathology,

University of Minnesota,

Minneapolis, MN, USA

D.-H. Lee

Department of Preventive Medicine, School of Medicine,

College of Medicine, Kyungpook National University,

Daegu, Korea

D. R. Jacobs Jr

Department of Nutrition, University of Oslo,

Oslo, Norway
HOMA-IR across CRP was attenuated but remained statistically significant after controlling for body fat measurements $(0.06$ in the highest vs lowest CRP in both crosssectional $[p$ value for trend $=0.001]$ and longitudinal analyses [ $p$ value for trend $=0.01]$ ), and was little changed by further adjustment for oxidative stress markers $\left(\mathrm{F}_{2}\right.$-isoprostanes and oxidised LDL). There were consistent increments in the levels of HOMA-IR with increasing concentrations of CRP over time. In contrast, higher HOMA-IR did not predict future increases in CRP. Findings were similar using fibrinogen as the predictor variable.

Conclusions/interpretation Although a substantial portion of this association was explained by obesity, CRP was independently related to concurrent and future insulin resistance.

Keywords Inflammation · Insulin resistance · Obesity

$\begin{array}{ll}\text { Abbreviations } \\ \text { CARDIA } & \text { Coronary Artery Risk Development in } \\ & \text { Young Adults } \\ \text { CRP } & \text { C-reactive protein } \\ \text { CVD } & \text { Cardiovascular disease } \\ \text { \%fat } & \text { Per cent body fat } \\ \text { GLM } & \text { Generalised linear model } \\ \text { GM } & \text { Geometric mean } \\ \text { HOMA-IR } & \text { Homeostasis model assessment of insulin } \\ & \text { resistance } \\ \text { IQR } & \text { Interquartile range } \\ \text { WC } & \text { Waist circumference } \\ \text { NEFA } & \text { Non-esterified fatty acid }\end{array}$

\section{Introduction}

Recent studies have reported that C-reactive protein (CRP), a marker of low-grade inflammation, is positively associ- 
ated with insulin resistance in prediabetic individuals, a relationship partially [1-3] or fully attenuated [4] by adjustment for obesity. No study, however, has yet reported the longitudinal relationship between low-grade inflammation and the development of insulin resistance, considering the role of adiposity and oxidative stress in this relationship. We explored whether previous cross-sectional findings were replicable in the longitudinal setting of the Coronary Artery Risk Development in Young Adults (CARDIA) study to better understand the underlying epidemiological pathways. In particular, we examined whether low-grade inflammation, measured by CRP, is an independent factor in the development of insulin resistance estimated by the homeostasis model assessment of insulin resistance (HOMA-IR) in a 5 year follow-up, controlling for body fat measurements and oxidative stress $[5,6]$.

We hypothesised that CRP predicts increased HOMA-IR, partly mediated by level of adiposity, in non-diabetic middleaged adults. In order to strengthen the hypothesised direction of the relationship, we tested the reciprocal relationship to see if elevated levels of HOMA-IR predicted increased CRP. We also report prediction using fibrinogen, which is elevated in inflammation and is related to CRP.

\section{Methods}

Study population CARDIA is a four-centre, populationbased longitudinal investigation of lifestyle and other factors that influence the development of cardiovascular disease (CVD). It began in 1985-86 with a cohort of 5,115 black and white men and women aged between 18 and 30 years. Of these, $90 \%, 86 \%, 81 \%, 79 \%, 74 \%$ and $72 \%$ of the surviving cohort members were re-examined at years 2 , $5,7,10,15$ and 20 , respectively.

In this analysis, we included all participants with CRP, fasting insulin, and fasting glucose measurements at years 7, 15 and 20. We excluded from our analysis those who had been diagnosed with diabetes, defined as ever having had a fasting glucose of $\geq 7 \mathrm{mmol} / 1$ or using glucose-lowering medication in years 0 to 20 .

Measurements Self-reported demographic and lifestyle information was collected via standardised questionnaires during each examination. Body mass index was calculated as weight/[height $(\mathrm{m})]^{2}$. Waist circumference $(\mathrm{WC}, \mathrm{cm})$ was measured halfway between the iliac crest and the bottom of the ribcage, with weight distributed equally on both feet.

To estimate the role of total body fatness in the association between CRP and HOMA-IR, race- and sex-specific estimates of per cent body fat (\%fat) were, in all participants, computed based on dual energy $\mathrm{x}$-ray absorptiometry performed in a subset at year 10. The estimates relied on race, sex, age, BMI,
WC and squared terms for waist circumference and BMI ( $\mathrm{WC}^{2}$ and $\mathrm{BMI}^{2}$ ). For black men, the equation was: \%fat= $-55.5371-0.0578 \times$ age $+0.1585 \times \mathrm{BMI}+1.1741 \times \mathrm{WC}-$ $0.00365 \times \mathrm{WC}^{2}$; for black women: $\%$ fat $=-52.0734+$ $0.0901 \times$ age $+1.9772 \times \mathrm{BMI}+0.9664 \times \mathrm{WC}-0.015 \times$ $\mathrm{BMI}^{2}-0.0051 \times \mathrm{WC}^{2}$; for white men: $\%$ fat $=-82.6174+$ $0.1015 \times$ age $+0.5448 \times \mathrm{BMI}+1.5883 \times \mathrm{WC}-0.0065 \times$ $\mathrm{WC}^{2}$; and for white women: $\%$ fat $=-75.2741+0.1698 \times$ age, $+1.2678 \times \mathrm{BMI}+1.7154 \times \mathrm{WC}-0.00972 \times \mathrm{WC}^{2}$. The correlations of per cent fat observed at year 10 with predicted values were $R^{2}: 0.66$ for black men, 0.76 for black women, 0.60 for white men, 0.74 for white women, and 0.82 for sex and race combined, compared with an $R^{2}$ of about 0.75 for the Durnin and Womersley [7] equations that relied solely on skinfold thicknesses.

Blood was taken by venepuncture during each examination. Participants were asked to fast for $12 \mathrm{~h}$ and to avoid smoking and heavy physical activity for at least $2 \mathrm{~h}$ prior to the examination. Serum was separated by centrifugation, transferred into airtight vials and stored at $-70^{\circ} \mathrm{C}$ until shipped on dry ice to a central laboratory.
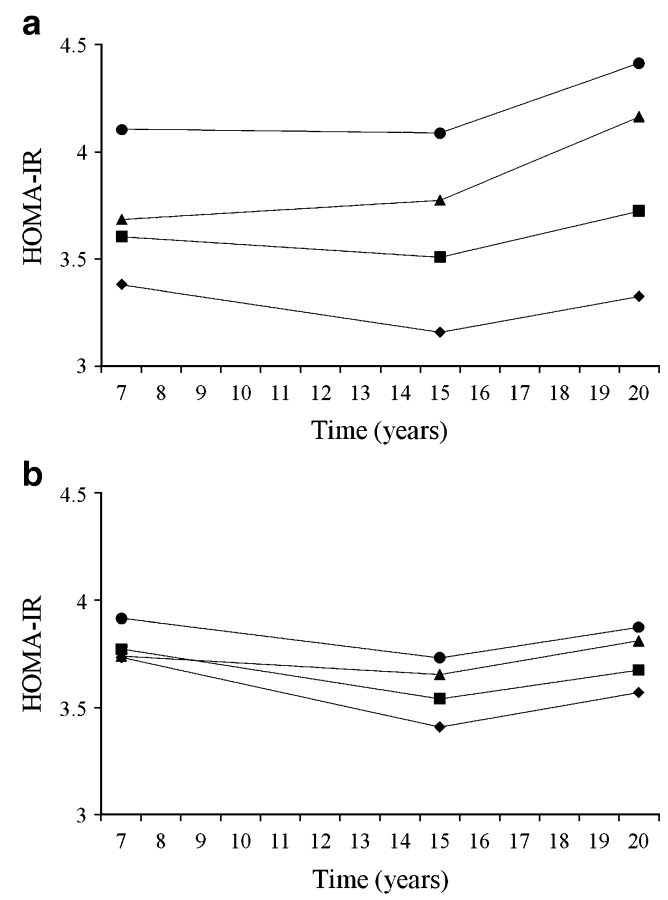

Fig. 1 Time pattern of HOMA-IR according to quartile of CRP based on both measurements at years 7, 15, and 20. a Model adjusted for year 7 covariates (sex, race, study centre, smoking status, physical activity, alcohol consumption and education) and age at years 7, 15 and 20. b Model as (a) plus waist circumference at years 7, 15 and 20. In the repeated measures regression model, $\log _{e}$ (HOMA-IR) measured at years 7,15 , and 20 was regressed on the corresponding repeated measures of $\log _{e}(\mathrm{CRP}) . \log _{e}[\mathrm{CRP}]$ quartile ranges: $0.13-<0.4$; $0.4-<0.8 ; 0.8-<1.2 ; 1.2-2.4$. First quartile, diamond; second quartile, square; third quartile, triangle; fourth quartile, circle 
The glucose and insulin measurements were performed at Linco Research (now Millipore, Inc., Billerica, MA, USA). The concentration of glucose in the stored serum samples was determined with a Cobas Mira Plus chemistry analyser (Roche Diagnostics, Indianapolis, IN, USA) and using the hexokinase ultraviolet method. The insulin measurements were performed by using a radioimmunoassay with an overnight, equilibriumincubation format. Based on re-assays of glucose in December 2007 in about 200 samples stored since year 7 and 100 samples stored since year 15, glucose and insulin concentrations were recalibrated to harmonise them with the previous measurements.
The biomarkers of oxidative stress were obtained at year 15 and/or year 20. Plasma $\mathrm{F}_{2}$ isoprostanes were measured at years 15 and 20 with gas chromatography-mass spectrometry. Serum oxidised LDL concentrations were measured by ELISA (Mercodia, Uppsala, Sweden) in year 15 samples [8] that had been stored at $-70^{\circ} \mathrm{C}$ for several years.

At years 7, 15 and 20, high-sensitivity enzyme-linked immunosorbent assays were used to measure serum CRP at the Department of Pathology, University of Vermont, Burlington, VT, USA. Fibrinogen was assayed at years 7 and 20 using the BNII nephelometer (Dade Behring, now Siemens Healthcare Diagnostics, Deerfield, IL, USA) in the

Table 1 Means (or proportions) of demographic, lifestyle and type 2 diabetes-related factors by quartiles of CRP at year 15

\begin{tabular}{|c|c|c|c|c|c|c|c|c|c|}
\hline \multirow[t]{3}{*}{ Characteristic/factor } & \multicolumn{9}{|c|}{ Quartiles of year 15 CRP } \\
\hline & \multicolumn{2}{|l|}{$1 \mathrm{st}$} & \multicolumn{2}{|l|}{ 2nd } & \multicolumn{2}{|l|}{$3 \mathrm{rd}$} & \multicolumn{2}{|l|}{4 th } & \multirow{2}{*}{$\begin{array}{l}p \text { value } \\
\text { for trend }\end{array}$} \\
\hline & $\begin{array}{l}\text { Mean or } \\
\text { GM }\end{array}$ & $\begin{array}{l}\text { SD or } \\
\text { IQR }\end{array}$ & $\begin{array}{l}\text { Mean or } \\
\text { GM }\end{array}$ & $\begin{array}{l}\text { SD or } \\
\text { IQR }\end{array}$ & $\begin{array}{l}\text { Mean or } \\
\text { GM }\end{array}$ & $\begin{array}{l}\text { SD or } \\
\text { IQR }\end{array}$ & $\begin{array}{l}\text { Mean or } \\
\text { GM }\end{array}$ & $\begin{array}{l}\text { SD or } \\
\text { IQR }\end{array}$ & \\
\hline$n$ & 760 & & 753 & & 755 & & 754 & & \\
\hline \multicolumn{10}{|l|}{ Demographics } \\
\hline Age (years) & 40.1 & 3.5 & 40.2 & 3.5 & 40.3 & 3.7 & 39.7 & 3.8 & 0.07 \\
\hline White, $\%$ & 65.0 & & 63.4 & & 53.1 & & 41.8 & & $<0.0001$ \\
\hline Male, $\%$ & 47.8 & & 52.5 & & 49.9 & & 32.2 & & $<0.0001$ \\
\hline $\begin{array}{l}\text { Education (grade of school } \\
\text { completed) }\end{array}$ & 15.3 & 2.6 & 15.2 & 2.5 & 14.8 & 2.5 & 14.7 & 2.4 & $<0.0001$ \\
\hline \multicolumn{10}{|l|}{ Lifestyle } \\
\hline Alcohol consumption (g/day) & 11.1 & 18.1 & 11.8 & 26.7 & 12.9 & 32.9 & 9.8 & 23.0 & 0.3 \\
\hline Physical activity (exercise units) & 369.7 & 280.8 & 387.2 & 292.8 & 367.8 & 297.3 & 300.3 & 270.0 & $<0.0001$ \\
\hline Current smoker, $\%$ & 17.4 & & 19.8 & & 25.3 & & 23.5 & & 0.02 \\
\hline \multicolumn{10}{|l|}{ Body fat components } \\
\hline Waist circumference $(\mathrm{cm})$ & 79.8 & 10.5 & 85.4 & 11.4 & 89.6 & 12.5 & 94.4 & 14.5 & $<0.0001$ \\
\hline BMI $\left(\mathrm{kg} / \mathrm{m}^{2}\right)$ & 24.3 & 3.7 & 26.5 & 4.4 & 28.2 & 5.2 & 31.8 & 7.0 & $<0.0001$ \\
\hline Estimated \%fat & 28.2 & 8.3 & 30.9 & 8.5 & 33.5 & 9.7 & 39.2 & 10.7 & $<0.0001$ \\
\hline \multicolumn{10}{|l|}{ Oxidative stress markers } \\
\hline $\mathrm{F}_{2}$-isoprostanes $(\mathrm{pmol} / \mathrm{l})$ & 136.9 & 4.7 & 143.0 & 4.7 & 151.1 & 5.0 & 173.1 & 5.5 & $<0.0001$ \\
\hline Oxidised LDL (U/1) & 69.40 & 1.58 & 74.37 & 1.53 & 79.70 & 1.53 & 80.92 & 1.52 & $<0.0001$ \\
\hline \multicolumn{10}{|l|}{ Inflammation markers } \\
\hline CRP at year 7 (mg/l) & 1.55 & 1.44 & 1.91 & 1.59 & 2.48 & 2.08 & 3.36 & 2.44 & $<0.0001$ \\
\hline CRP at year 15 (mg/l) & 1.29 & 1.18 & 1.77 & 1.19 & 2.79 & 1.33 & 5.97 & 1.66 & $<0.0001$ \\
\hline CRP at year $20(\mathrm{mg} / \mathrm{l})$ & 1.47 & 1.35 & 1.92 & 1.55 & 2.56 & 1.88 & 3.86 & 2.51 & $<0.0001$ \\
\hline Fibrinogen at year $7(\mu \mathrm{mol} / \mathrm{l})$ & 8.90 & 1.80 & 9.22 & 1.78 & 9.67 & 1.84 & 10.67 & 2.14 & $<0.0001$ \\
\hline Fibrinogen at year $20(\mu \mathrm{mol} / \mathrm{l})$ & 10.57 & 1.97 & 11.14 & 2.20 & 11.80 & 2.23 & 12.94 & 2.66 & $<0.0001$ \\
\hline \multicolumn{10}{|l|}{ HOMA-IR } \\
\hline HOMA-IR at year 7 & 3.22 & 1.38 & 3.47 & 1.42 & 3.64 & 1.46 & 3.99 & 1.60 & $<0.0001$ \\
\hline HOMA-IR at year 15 & 3.04 & 1.44 & 3.46 & 1.54 & 3.84 & 1.67 & 4.35 & 1.76 & $<0.0001$ \\
\hline HOMA-IR at year 20 & 3.27 & 1.45 & 3.69 & 1.63 & 4.09 & 1.70 & 4.59 & 1.72 & $<0.0001$ \\
\hline
\end{tabular}

All variables were measured at year 15 unless stated otherwise

HOMA-IR, oxidative stress markers and CRP were logarithmically transformed for the purpose of analysis, and geometric means and interquartile ranges are presented 
Table 2 Partial correlation coefficients of measured CRP at year 7, 15 or 20 with fibrinogen at year 7 or 20: the CARDIA study, 1992-2006

\begin{tabular}{lcccc}
\hline Variable & $n$ & $\begin{array}{c}\text { CRP at } \\
\text { year 7 }\end{array}$ & $\begin{array}{l}\text { CRP at } \\
\text { year 15 }\end{array}$ & $\begin{array}{l}\text { CRP at } \\
\text { year 20 }\end{array}$ \\
\hline CRP at year 7 & 2,253 & 1 & 0.51 & 0.46 \\
CRP at year 15 & & & 1 & 0.61 \\
CRP at year 20 & & & & 1 \\
Fibrinogen at year 7 & 2,220 & 0.53 & 0.27 & 0.24 \\
Fibrinogen at year 20 & 2,220 & 0.27 & 0.32 & 0.50 \\
\hline
\end{tabular}

All models were adjusted for age, sex and race

$p<0.01$ for all correlations

same laboratory [9]. A common protocol and qualitycontrol procedures were used for all examinations.

Statistical analysis HOMA-IR was calculated using the formula, as described by Matthews et al. [10], which used the formula fasting plasma insulin $(\mu \mathrm{IU} / \mathrm{l}) \times$ fasting plasma glucose $(\mathrm{mmol} / \mathrm{l}) / 22.5$. When insulin is expressed in SI units as pmol/l, the constant changes to 156.26 . BMI and WC were set to missing at each examination at which a woman was pregnant. CRP concentrations greater than $10 \mathrm{mg} / \mathrm{l}$ were set to missing (possible acute inflammatory condition). Markers with skewed (non-normal) distributions, such as HOMA-IR, were logarithmically transformed to approximate normality.

Cross-sectional associations were studied between year 15 CRP and year 15 HOMA-IR using multivariable generalised linear models (GLMs). Longitudinal associations were then studied between year $15 \mathrm{CRP}$ as the independent variable of interest and year 20 HOMA-IR as the dependent variable, including year 15 HOMA-IR as an independent variable in the GLMs. Generalised linear mixed models were employed to examine the time patterns of HOMA-IR according to the concentration of CRP, adjusting for demographic and lifestyle factors. In these models, repeated HOMA-IR measurements at years $7,10,15$ and 20 were regressed on time in categories of CRP variable, repeatedly measured at years 7,15 and 20, shown in Fig. 1. Parallel analyses used fibrinogen as the predictor variable of interest.

All observed cross-sectional and longitudinal associations were examined as a measure of goodness of fit of the repeated-measures model. To study whether the associations were detectable in the reverse direction, CRP concentration was used as the dependent variable predicted by HOMA-IR in the GLMs.

There were no significant interactions in the prediction of HOMA-IR between CRP and other covariates, including sex, race, smoking, alcohol consumption, physical activity or adiposity measurements. All analyses were performed with SAS version 9.1 (SAS Institute, Cary, NC, USA).

\section{Results}

At year 15 (2000-2001), the mean age of the participants was 40 years, $56 \%$ were white, and $46 \%$ were men. Of the 3,022 participants with no missing data for CRP at year 15, those with higher CRP concentrations were more likely to be black, less educated and smokers (Table 1). HOMA-IR, fibrinogen, both body fatness measures and oxidative stress markers increased with CRP concentration (Table 1).

CRP at year 15 was strongly associated with CRP at years 7 and 20, with correlations of 0.51 and 0.61 , respectively, and fibrinogen had a correlation of 0.5 with concurrent CRP (Table 2). Tracking correlations for HOMA-IR ranged from 0.41 to 0.61 (Table 3).

In the cross-sectional analysis, year $15 \mathrm{CRP}$ was a significant correlate of year 15 HOMA-IR, adjusting for demographic and lifestyle factors (Table 4). The association between CRP and HOMA-IR was still evident after additional adjustment for adiposity measurements, although the differences in HOMA-IR between the quartiles of CRP were attenuated. Further adjustment for the biomarkers of oxidative stress (model 4) did not affect this association. The findings were similar in cross-sectional associations between year 7 CRP and year 7 HOMA-IR and between year $20 \mathrm{CRP}$ and year 20 HOMA-IR (Table 5).

The longitudinal analysis in Table 4, in which the level of year 20 HOMA-IR was predicted, adjusting for year 15 HOMA-IR and demographic/lifestyle factors, showed a substantial independent increase in the estimates of evolving HOMA-IR with increasing concentrations of CRP $(p<0.0001)$. After additional adjustment for the adiposity measurements, an attenuated positive association
Table 3 Partial correlation coefficients of measured HOMA-IR at year 7, 10, 15 or 20: the CARDIA study, 1992-2006

All models were adjusted for age, sex and race $p<0.01$ for all correlations

\begin{tabular}{lccccc}
\hline Variable & $n$ & $\begin{array}{c}\text { HOMA-IR } \\
\text { at year 7 }\end{array}$ & $\begin{array}{c}\text { HOMA-IR } \\
\text { at year 10 }\end{array}$ & $\begin{array}{c}\text { HOMA-IR } \\
\text { at year 15 }\end{array}$ & $\begin{array}{c}\text { HOMA-IR } \\
\text { at year 20 }\end{array}$ \\
\hline HOMA-IR at year 7 & 2,348 & 1 & 0.55 & 0.47 & 0.41 \\
HOMA-IR at year 10 & & & 1 & 0.57 & 0.50 \\
HOMA-IR at year 15 & & & 1 & 0.61 \\
HOMA-IR at year 20 & & & & 1 \\
\hline
\end{tabular}


Table 4 Cross-sectional and longitudinal relationships between CRP (quartile) and HOMA-IR (continuous)

Insulin resistance: beta-coefficient ${ }^{\mathrm{a}}$ per quartile of year $15 \mathrm{CRP}$

\begin{tabular}{|c|c|c|c|c|c|c|c|c|c|c|}
\hline \multirow[b]{2}{*}{ Adjustments } & \multicolumn{5}{|c|}{ Cross-sectional association ${ }^{\mathrm{b}}$} & \multicolumn{5}{|c|}{ Longitudinal association $^{\mathrm{c}}$} \\
\hline & $1 \mathrm{st}$ & 2nd & $3 \mathrm{rd}$ & 4 th & $p$ value for trend & $1 \mathrm{st}$ & 2 nd & $3 \mathrm{rd}$ & 4th & $p$ value for trend \\
\hline Model $1^{\mathrm{d}}$ & Ref. & 0.1234 & 0.2193 & 0.3514 & $<0.0001$ & Ref. & 0.0330 & 0.0767 & 0.1140 & $<0.0001$ \\
\hline Model $2^{\mathrm{e}}$ & Ref. & 0.1227 & 0.2167 & 0.3423 & $<0.0001$ & Ref. & 0.0353 & 0.0792 & 0.1186 & $<0.0001$ \\
\hline \multicolumn{11}{|l|}{ Model $3^{\mathrm{f}}$} \\
\hline BMI $\left(\mathrm{kg} / \mathrm{m}^{2}\right)$ & Ref. & 0.0470 & 0.0833 & 0.0937 & $<0.0001$ & Ref. & 0.0225 & 0.0515 & 0.0657 & 0.001 \\
\hline $\mathrm{WC}(\mathrm{cm})$ & Ref. & 0.0283 & 0.0454 & 0.0575 & 0.001 & Ref. & 0.0167 & 0.0388 & 0.0516 & 0.01 \\
\hline Estimated $\%$ fat & Ref. & 0.0247 & 0.0488 & 0.0783 & $<0.0001$ & Ref. & 0.0152 & 0.0404 & 0.0594 & 0.002 \\
\hline Model $4^{\mathrm{g}}$ & Ref. & 0.0230 & 0.0274 & 0.0557 & 0.004 & Ref. & 0.0181 & 0.0308 & 0.0499 & 0.02 \\
\hline
\end{tabular}

${ }^{a}$ The beta coefficient is approximately the proportion increase in the geometric mean HOMA-IR compared with the lowest quartile of CRP

${ }^{\mathrm{b}}$ In cross-sectional analyses, CRP and HOMA-IR were measured at year 15

${ }^{\mathrm{c}}$ In longitudinal analyses, CRP was measured at year 15 and HOMA-IR was measured at year 20

${ }^{\mathrm{d}}$ Model 1: adjusting for age, sex, race and study centre. Year 15 HOMA-IR was additionally included in longitudinal analysis

${ }^{\mathrm{e}}$ Model 2: model 1 plus year 15 smoking status, physical activity, alcohol consumption and education

${ }^{\mathrm{f}}$ Model 3: model 2 plus body fat measurements (BMI, WC or estimated \%fat in three separate models)

${ }^{\mathrm{g}}$ Model 4: model 2 plus WC, F2-isoprostanes and oxidised LDL

Ref. Reference

between CRP and HOMA-IR persisted. Adiposity measurements remain significant in the models adjusted for CRP (data not shown, $p<0.0001$ ). As year 15 HOMA-IR is included in the model, the dependent variable may be interpreted as the development of HOMA-IR between years 15 and 20. In addition, in examination of a possible feedback loop between CRP and HOMA-IR, the predictability of year 20 CRP from year 15 HOMA-IR was not statistically significant when controlling for demographic, lifestyle factors, body fat measurements and CRP, each measured in the same year as independent variables (regression coefficient $0.0129, p=0.7$ ).

As with CRP, fibrinogen was correlated with HOMA-IR cross-sectionally at years 7 and 20 (Table 5). Year 7 fibrinogen predicted the development of HOMA-IR from year 7 to year 20. Adjustment for body fatness attenuated these associations, which remained statistically significant for an 8 year follow-up period, but for 13 years follow-up. In joint models, both CRP and fibrinogen predicted HOMA-IR (data not shown).

Figure 1 shows the time pattern of HOMA-IR according to the quartiles of CRP over time. There were consistent increments in the levels of HOMA-IR, with increasing categories of CRP at each examination. The levels of HOMA-IR consistently increased with time, except those with the lowest concentration of CRP. After adjustment for WC, these relationships weakened. However, the levels of HOMA-IR still increased consistently with increasing CRP over time.

\section{Discussion}

This large community-based study shows that CRP, a marker of low-grade inflammation, was associated with insulin resistance both cross-sectionally and longitudinally with the development of insulin resistance in a 5 year follow-up, even after accounting for adiposity measurements and oxidative stress markers. In addition, we observed these positive associations consistently over time in a sample of healthy adults with an average age range of $40-45$ years. Given that the associations between CRP and insulin resistance were attenuated after adjustment for body fat measurements, adiposity may play an important role in the aetiological relationship between CRP and insulin resistance; however, a substantial part of this association was still not explained by obesity, pointing to CRP as an obesity-independent signal of other factors important in the development of insulin resistance.

Recent cross-sectional studies [1-3] have shown CRP to be positively associated with insulin resistance in non-diabetic individuals, presenting a significant role of obesity in this association. Our study results add further support for the current understanding that CRP is independently correlated with concurrent insulin resistance. In addition, consistent with recent findings, a novel finding of our study is that CRP predicted the development of subsequent insulin resistance, independent of obesity and oxidative stress, in healthy young people in a large community-based setting. Adding specificity to this finding, higher levels of HOMA-IR did not predict future CRP concentrations. Fibrinogen, which correlates with 
Table 5 Cross-sectional and longitudinal relationships between inflammation markers (CRP [continuous, $\log _{e}$ scale] and fibrinogen [continuous, original scale]) and HOMA-IR (continuous, $\log _{e}$ scale)

\begin{tabular}{|c|c|c|c|c|c|}
\hline Independent variable & Dependent variable & Adjustments & Estimate & $\mathrm{SE}$ & $p$ value \\
\hline \multicolumn{6}{|l|}{ Cross-sectional $^{\mathrm{a}}$} \\
\hline \multirow[t]{4}{*}{ Year 7 CRP } & \multirow[t]{4}{*}{ Year 7 HOMA-IR } & Confounders only ${ }^{\mathrm{b}}$ & 0.1872 & 0.0106 & $<0.0001$ \\
\hline & & BMI $\left(\mathrm{kg} / \mathrm{m}^{2}\right)^{\mathrm{c}}$ & 0.0496 & 0.0106 & $<0.0001$ \\
\hline & & $\mathrm{WC}(\mathrm{cm})^{\mathrm{d}}$ & 0.0346 & 0.0102 & 0.0007 \\
\hline & & Estimated $\% \mathrm{fat}^{\mathrm{e}}$ & 0.0476 & 0.0104 & $<0.0001$ \\
\hline \multirow[t]{4}{*}{ Year 15 CRP } & \multirow[t]{4}{*}{ Year 15 HOMA-IR } & Confounders only ${ }^{\mathrm{b}}$ & 0.2128 & 0.0117 & $<0.0001$ \\
\hline & & BMI $\left(\mathrm{kg} / \mathrm{m}^{2}\right)^{\mathrm{c}}$ & 0.0552 & 0.0115 & $<0.0001$ \\
\hline & & $\mathrm{WC}(\mathrm{cm})^{\mathrm{d}}$ & 0.0355 & 0.0111 & 0.001 \\
\hline & & Estimated \%fat ${ }^{\mathrm{e}}$ & 0.0504 & 0.0113 & $<0.0001$ \\
\hline \multirow[t]{4}{*}{ Year 20 CRP } & \multirow[t]{4}{*}{ Year 20 HOMA-IR } & Confounders only ${ }^{b}$ & 0.2367 & 0.0119 & $<0.0001$ \\
\hline & & BMI $\left(\mathrm{kg} / \mathrm{m}^{2}\right)^{\mathrm{c}}$ & 0.1028 & 0.0123 & $<0.0001$ \\
\hline & & $\mathrm{WC}(\mathrm{cm})^{\mathrm{d}}$ & 0.0610 & 0.0120 & $<0.0001$ \\
\hline & & Estimated \%fat ${ }^{\mathrm{e}}$ & 0.0842 & 0.0122 & $<0.0001$ \\
\hline \multirow[t]{4}{*}{ Year 7 fibrinogen } & \multirow[t]{4}{*}{ Year 7 HOMA-IR } & Confounders only ${ }^{\mathrm{b}}$ & 0.0551 & 0.0029 & $<0.0001$ \\
\hline & & BMI $\left(\mathrm{kg} / \mathrm{m}^{2}\right)^{\mathrm{c}}$ & 0.0162 & 0.0029 & $<0.0001$ \\
\hline & & $\mathrm{WC}(\mathrm{cm})^{\mathrm{d}}$ & 0.0139 & 0.0028 & $<0.0001$ \\
\hline & & Estimated \%fat ${ }^{\mathrm{e}}$ & 0.0161 & 0.0028 & $<0.0001$ \\
\hline \multirow[t]{4}{*}{ Year 20 fibrinogen } & \multirow[t]{4}{*}{ Year 20 HOMA-IR } & Confounders only ${ }^{\mathrm{b}}$ & 0.0412 & 0.0029 & $<0.0001$ \\
\hline & & BMI $\left(\mathrm{kg} / \mathrm{m}^{2}\right)^{\mathrm{c}}$ & 0.0109 & 0.0028 & $<0.0001$ \\
\hline & & $\mathrm{WC}(\mathrm{cm})^{\mathrm{d}}$ & 0.0048 & 0.0027 & 0.07 \\
\hline & & Estimated $\% \mathrm{fat}^{\mathrm{e}}$ & 0.0081 & 0.0028 & 0.003 \\
\hline \multicolumn{6}{|l|}{ Longitudinal $^{\mathrm{a}}$} \\
\hline \multirow[t]{4}{*}{ Year 7 CRP } & \multirow[t]{4}{*}{ Year 15 HOMA-IR } & Confounders only ${ }^{\mathrm{b}}$ & 0.1162 & 0.0132 & $<0.0001$ \\
\hline & & $\operatorname{BMI}\left(\mathrm{kg} / \mathrm{m}^{2}\right)^{\mathrm{c}}$ & 0.0549 & 0.0138 & $<0.0001$ \\
\hline & & $\mathrm{WC}(\mathrm{cm})^{\mathrm{d}}$ & 0.0442 & 0.0137 & 0.001 \\
\hline & & Estimated $\%$ fat $^{\mathrm{e}}$ & 0.0474 & 0.0137 & 0.0005 \\
\hline \multirow[t]{4}{*}{ Year 7 CRP } & \multirow[t]{4}{*}{ Year 20 HOMA-IR } & Confounders only ${ }^{\mathrm{b}}$ & 0.0861 & 0.0145 & $<0.0001$ \\
\hline & & BMI $\left(\mathrm{kg} / \mathrm{m}^{2}\right)^{\mathrm{c}}$ & 0.0410 & 0.0156 & 0.009 \\
\hline & & $\mathrm{WC}(\mathrm{cm})^{\mathrm{d}}$ & 0.0273 & 0.0155 & 0.08 \\
\hline & & Estimated \%fat ${ }^{\mathrm{e}}$ & 0.0276 & 0.0155 & 0.07 \\
\hline \multirow[t]{4}{*}{ Year 15 CRP } & \multirow[t]{4}{*}{ Year 20 HOMA-IR } & Confounders only ${ }^{\mathrm{b}}$ & 0.0728 & 0.0114 & $<0.0001$ \\
\hline & & BMI $\left(\mathrm{kg} / \mathrm{m}^{2}\right)^{\mathrm{c}}$ & 0.0398 & 0.0121 & 0.001 \\
\hline & & $\mathrm{WC}(\mathrm{cm})^{\mathrm{d}}$ & 0.0312 & 0.0120 & 0.01 \\
\hline & & Estimated \%fat ${ }^{\mathrm{e}}$ & 0.0370 & 0.0120 & 0.002 \\
\hline \multirow[t]{4}{*}{ Year 7 fibrinogen } & \multirow[t]{4}{*}{ Year 15 HOMA-IR } & Confounders only ${ }^{\mathrm{b}}$ & 0.0248 & 0.0036 & $<0.0001$ \\
\hline & & BMI $\left(\mathrm{kg} / \mathrm{m}^{2}\right)^{\mathrm{c}}$ & 0.0090 & 0.0038 & 0.02 \\
\hline & & $\mathrm{WC}(\mathrm{cm})^{\mathrm{d}}$ & 0.0084 & 0.0037 & 0.02 \\
\hline & & Estimated \%fat ${ }^{\mathrm{e}}$ & 0.0070 & 0.0037 & 0.06 \\
\hline \multirow[t]{4}{*}{ Year 7 fibrinogen } & \multirow[t]{4}{*}{ Year 20 HOMA-IR } & Confounders only ${ }^{\mathrm{b}}$ & 0.0170 & 0.0041 & $<0.0001$ \\
\hline & & BMI $\left(\mathrm{kg} / \mathrm{m}^{2}\right)^{\mathrm{c}}$ & 0.0073 & 0.0043 & 0.1 \\
\hline & & $\mathrm{WC}(\mathrm{cm})^{\mathrm{d}}$ & 0.0052 & 0.0043 & 0.2 \\
\hline & & Estimated $\% \mathrm{fat}^{\mathrm{e}}$ & 0.0042 & 0.0043 & 0.3 \\
\hline
\end{tabular}

${ }^{a}$ The estimate is the increase in the mean $\log _{e}$ (HOMA-IR) per unit of the given inflammation marker. All covariates were measured in the same year as CRP or fibrinogen. HOMA-IR and CRP were logarithmically transformed for the purposes of analysis. Patients diagnosed with diabetes at or before the examination at which CRP/ fibrinogen was measured were excluded from the analyses

${ }^{\mathrm{b}}$ Model 1: adjusting for age, sex, race, study centre, smoking status, physical activity, alcohol consumption and education. HOMA-IR measured in the same year with inflammation markers was additionally included in longitudinal analyses

${ }^{\mathrm{c}}$ Model 2: model 1 plus BMI

${ }^{\mathrm{d}}$ Model 3: model 1 plus WC

${ }^{\mathrm{e}}$ Model 4: model 1 plus estimated \%fat for markers of obesity. However, this study was limited by the uncertain temporality, given its cross-sectional design, and had a relatively small sample size of 364 study volunteers recruited in one study centre in Utrecht, the Netherlands; thus, the study results may have limited statistical power and representativeness. 
Another mechanism - the activation of inflammatory pathways by oxidative stress $[5,6]$ - has been suggested. Once the concentration of glucose is increased under hyperglycaemic conditions, it causes an excess production of reactive oxygen species in mitochondria, resulting in oxidative damage and inflammation [5]. In vivo studies have supported the finding that both cumulative NEFA and glucose induce inflammation through oxidative stress [6]; however, our study results showed the relationship between CRP and insulin resistance was not fully explained by oxidative stress markers (oxidised LDL and $\mathrm{F}_{2}$-isoprostanes). Oxidative stress is a highly complex phenomenon, and our measures may not be sufficiently detailed to fully explain the role of oxidative stress in the association of chronic lowgrade inflammation in the development of insulin resistance. However, it is noteworthy that oxidised LDL is a strong predictor of future metabolic syndrome in CARDIA [8]. Thus, although insulin resistance has been thought to be fundamental in metabolic syndrome, we have here shown several ways in which these phenomena part ways.

Our study results confirm that adipose tissue may play an important role in the relationship between CRP and insulin resistance, showing that a substantial portion of this association was explained by body fatness measurements. It is consistent with the theory that adipocytes secrete proinflammatory cytokines (such as IL-6, TNF- $\alpha$ and IL-18), which were overproduced in the adipose tissue of obese individuals [11-14], and positively correlated with insulin resistance [12-14]. However, our results, as well as previous studies $[2,15]$ reporting an obesity-independent association that relates CRP and insulin resistance, imply that another pathophysiological pathway of obesityindependent inflammatory reaction may enhance insulin resistance among non-diabetic individuals. Little is yet known about the causes of this obesity-independent CRP association with insulin resistance. Additional research is warranted to examine the extent to which factors are linked with this pathophysiological pathway of obesity-independent inflammatory reaction and whether CRP is causal, for example through study of genetic factors [16].

The present study has several strengths. No previous studies have examined the longitudinal associations between inflammation and insulin resistance, especially with the primary aim of exploring the underlying pathways for the effect of obesity in this association in large communitybased study. In addition, we were able to test our hypothesis over various time frames, confirming that this association was not affected much by period effects (population-wide changes over calendar time) or by age effects. We could confirm the findings using a related marker, fibrinogen. Furthermore, we tested prediction in the reverse direction and added to the specificity of our findings by showing that HOMA-IR did not predict future CRP.
A limitation of the study is that other adiposity measurements, such as total fat mass or per cent fat, were not measured for the entire group of study participants throughout the period of the study; thus, we could not estimate the effect of directly measured body fatness in the relationship of CRP with insulin resistance. In addition, the study was conducted only among black and white individuals; thus, the conclusions from this study may not be applicable to all populations. Finally, there could be residual confounding as in all observational studies, including the likelihood that we could not account through our existing anthropometric measures for all nuances related to obesity. The epidemiological measures may lack the specificity that would be required to make judgements about the causal pathways from obesity to the development of insulin resistance through inflammation.

In conclusion, our results show that increased circulating $\mathrm{CRP}$ is associated with current and future insulin resistance in early adult life. Although there was an obesity-independent association of CRP with insulin resistance, a substantial fraction of this association was explained by obesity. In addition, oxidative stress did not explain the remaining portion of this association after controlling for adiposity.

Acknowledgements Source of funding: this research was supported by contracts N01-HC-95095, N01-HC-48047, N01-HC-48048, and N01-HC-48049 and a grant R01-HL-53560, all from the National Heart, Lung, and Blood Institute, National Institutes of Health, Coronary Artery Risk De velopment in Young Adults (CARDIA study).

Duality of interest The authors declare that there is no duality of interest associated with this manuscript.

\section{References}

1. Nakanishi N, Shiraishi T, Wada M (2005) Association between Creactive protein and insulin resistance in a Japanese population: the Minoh Study. Intern Med 44:542-547

2. Meng YX, Ford ES, Li C et al (2007) Association of C-reactive protein with surrogate measures of insulin resistance among nondiabetic US from National Health and Nutrition Examination Survey 1999-2002. Clin Chem 53:2152-2159

3. Santos AC, Lopes C, Guimaraes JT, Barros H (2005) Central obesity as a major determinant of increased high-sensitivity Creactive protein in metabolic syndrome. Int J Obes 29:1452-1456

4. Niehoff AG, van Haeften TW, Onland-Moret NC, Elbers CC, Wijmenga C, van der Schouw YT (2007) C-reactive protein is independently associated with glucose but not with insulin resistance in healthy men. Diabetes Care 30:1627-1629

5. Brownlee M (2001) Biochemistry and molecular cell biology of diabetic complications. Nature 414:813-820

6. Ceriello A, Motz E (2004) Is oxidative stress the pathogenic mechanism underlying insulin resistance, diabetes, and cardiovascular disease? The common soil hypothesis revisited. Arterioscler Thromb Vasc Biol 24:816-823

7. Durnin JV, Womersley J (1974) Body fat assessed from total body density and its estimation from skinfold thickness: measurements on 481 men and women aged from 16 to 72 years. Br J Nutr 32:77-97 
8. Holvoet P, Lee DH, Steffes M, Gross M, Jacobs DR Jr (2008) Association between circulating oxidized low-density lipoprotein and incidence of the metabolic syndrome. JAMA 299:22872293

9. Thyagarajan B, Jacobs DR, Apostol GG, Smith LJ, Lewis CE, Williams OD (2006) Plasma fibrinogen and lung function: the CARDIA Study. Int J Epidemiol 35:1001-1008

10. Matthews DR, Hosker JP, Rudenski AS, Naylor BA, Treacher DF, Turner RC (1985) Homeostasis model assessment: insulin resistance and beta-cell function from fasting plasma glucose and insulin concentrations in man. Diabetologia 28:412-419

11. Hotamisligil GS, Shargill NS, Spiegelman BM (1993) Adipose expression of tumor necrosis factor-alpha: direct role in obesitylinked insulin resistance. Science 259:87-89

12. Kern PA, Saghizadeh M, Ong JM, Bosch RJ, Deem R, Simsolo RB (1995) The expression of tumor necrosis factor in human adipose tissue. Regulation by obesity, weight loss, and relationship to lipoprotein lipase. J Clin Invest 95:2111-2119

13. Hotamisligil GS, Arner P, Caro JF, Atkinson RL, Spiegelman BM (1995) Increased adipose tissue expression of tumor necrosis factor-alpha in human obesity and insulin resistance. J Clin Invest 95:2409-2415

14. Saghizadeh M, Ong JM, Garvey WT, Henry RR, Kern PA (1996) The expression of TNF alpha by human muscle. Relationship to insulin resistance. J Clin Invest 97:1111-1116

15. Yudkin JS, Stehouwer CD, Emeis JJ, Coppack SW (1999) Creactive protein in healthy subjects: associations with obesity, insulin resistance, and endothelial dysfunction: a potential role for cytokines originating from adipose tissue? Arterioscler Thromb Vasc Biol 19:972-978

16. Zacho J, Tybjaerg-Hansen A, Jensen JS, Grande P, Sillesen H, Nordestgaard BG (2008) Genetically elevated C-reactive protein and ischemic vascular disease. N Engl J Med 359:1897-1908 